\title{
Exosomal transfer of p-STAT3 promotes acquired 5-FU resistance in colorectal cancer cells
}

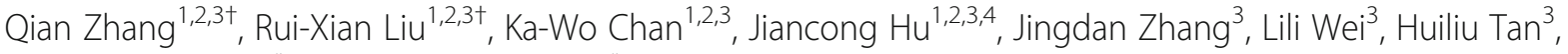
Xiangling Yang ${ }^{1,2,3^{*}}$ and Huanliang Liu i, $^{1,33^{*}}$

\begin{abstract}
Background: Acquired resistance remains a limitation of the clinical use of 5-fluorouracil (5-FU). Because exosomes, are important vesicles participating in intercellular communication, their contribution to the development of acquired 5-FU resistance needs to be elucidated. In this study, we aimed to examine the underlying mechanisms of exosomes from 5-FU resistant cells (RKO/R) in sustaining acquired 5-FU resistance in sensitive cells (RKO/P).

Methods: Exosomes from a 5-FU-resistant cell line (RKO/R) and its parental cell line RKO/P were isolated and co-cultured with 5-FU-sensitive cells. Real-time cellular analysis (RTCA) and FACS analysis were used to examine cell viability and apoptosis. Exosomal protein profiling was performed using shotgun proteomics. Inhibitors and siRNAs were applied to study the involvement of selected proteins in 5-FU resistance. The effect of exosomal p-STAT3 (Tyr705) on the caspase cascade was examined by western blotting (WB) and high content analysis. Xenograft models were established to determine whether exosomal p-STAT3 can induce 5-FU resistance in vivo.

Results: Our results indicated that exosomes from RKO/R cells significantly promoted cell survival during 5-FU treatment. Proteomics and WB analysis results indicated that GSTP1 and p-STAT3 (Tyr705) were enriched in exosomes from RKO/R cells. Inhibition of p-STAT3 re-sensitized RKO/P cells to 5-FU via caspase cascade. Furthermore, p-STAT3 packaged by exosomes from RKO/R cells increased resistance of tumor cells to 5-FU in vivo.

Conclusions: Our results reveal a novel mechanism by which p-STAT3-containing exosomes contribute to acquired 5-FU resistance in CRC. This study suggests a new option for potentiating the 5-FU response and finding biomarkers for chemotherapy resistance.
\end{abstract}

Keywords: P-STAT3, Exosomes, 5-FU resistance, Colorectal cancer

\section{Background}

Colorectal cancer $(\mathrm{CRC})$ is one of the most common cancer in the world, ranking as the fourth diagnosed cancer [1]. Since 5-fluorouracil (5-FU) was discovered in 1957 [2], it has been used as first-line therapy in colorectal cancer [3]. Despite this, the efficacy of 5-FU-based chemotherapy is disappointing [4]. Most patients acquire resistance during treatment with a median survival of approximately 20 months $[5,6]$. Thus, resistance to

\footnotetext{
* Correspondence: yangxI28@mail.sysu.edu.cn; liuhuan|@mail.sysu.edu.cn ${ }^{\dagger}$ Qian Zhang and Rui-Xian Liu contributed equally to this work.

'Guangdong Institute of Gastroenterology, The Sixth Affiliated Hospital, Sun Yat-sen University, Guangzhou 510655, Guangdong, China

Full list of author information is available at the end of the article
}

5-FU-based chemotherapy has become the major hurdle to improve treatment efficacy.

The mechanisms of 5-FU resistance are complex. Some studies have demonstrated that cancer cells are resistant to chemotherapy intrinsically. Mutant p53 tumor suppressor gene is found in many human tumors and its activity is associated with 5-FU resistance [7]. Some members of $\mathrm{Bcl}-2$ family, such as $\mathrm{Bcl}-\mathrm{xL}$ and $\mathrm{Bax}$, are related to 5-FU resistance in colorectal cancer [8]. Overexpression of Astrocyte elevated gene-1 (AEG-1) increases 5-FU resistance in human hepatocellular carcinoma (HCC) [9]. While other studies have indicated that drug resistance could be acquired. Tumor microenvironment includes many stromal cells and plays a critical role in

(C) The Author(s). 2019 Open Access This article is distributed under the terms of the Creative Commons Attribution 4.0 International License (http://creativecommons.org/licenses/by/4.0/), which permits unrestricted use, distribution, and 
chemoresistance. Cancer-associated fibroblasts (CAFs) are capable of decreasing drug uptake in tumors and causing resistance during chemotherapy [10]. Tumor associated macrophages (TAMs) could protect colorectal cancer cells from 5-FU-based chemotherapy via putrescine [11]. In triple-negative breast cancer, TGF- $\beta$ increases the stem-like properties of cancer cells and causes drug-resistance [12].

Exosomes secreted by different kinds of cells are a kind of vesicles consisted of lipid bilayer membrane and play important roles in cell to cell communication [13]. These vesicles contain various proteins and nucleic acids including mRNAs and microRNAs [14, 15]. Recent studies have indicated that exosomes display multiple roles in tumor progression. Exosomes from mesenchymal stem cells could transfer angiogenesis-related microRNAs [16]. Exosomal microRNA-9 released by nasopharyngeal carcinoma cells inhibits angiogenesis by targeting MDK and is associated with good survival in patients [17]. MicroRNA-103 secreted by hepatoma cells is capable of promoting tumor cell metastasis [18]. Metastatic organotropism is associated with exosomes and the integrins of exosomes could be used to predict tumor metastasis [19]. Until now, most studies have focused on exosomal microRNAs transfer in various cancers. However, the mechanisms by which proteins in exosomes affect the phenotype of recipient cells have not been fully interpreted, especially in chemotherapy resistance.

Taken together, these findings promote us to investigate whether exosomes derived from 5-FU resistant cells could mediate 5-FU resistance in colorectal cancer cells. We verified the function of exosomes from 5-FU resistant cells $\mathrm{RKO} / \mathrm{R}$ (Exo/R), analyzed the proteomics results of Exo/R and RNA-sequencing of 5-FU sensitive cells $(\mathrm{RKO} / \mathrm{P})$ and resistant cells $(\mathrm{RKO} / \mathrm{R})$. By doing this, we found that exosomal p-STAT3 enhanced 5-FU resistance in sensitive cells $(\mathrm{RKO} / \mathrm{P})$ via caspase cascade. Our results may open new avenues for discovering diagnostic markers and therapeutic targets for acquired 5FU resistance.

\section{Methods}

\section{Cell culture}

Human colorectal cancer cell lines RKO and HCT116 were purchased from the Chinese Academy of Science (Shanghai, China). A 5-FU resistant cell line (RKO/R) was established from RKO parental cell line (RKO/P) as previously described [20]. RKO/P and RKO/R cells were cultured in DMEM (Gibco, USA), and HCT116 cells were cultured in RPMI-1640 medium (Gibco, USA). $\mathrm{RKO} / \mathrm{R}$ cells were cultured without 5-FU for this experiment. All medium contained 10\% FBS (Gibco USA) and a penicillin-streptomycin solution (Gibco, USA). Cells were incubated in a humidified incubator with $5 \% \mathrm{CO}_{2}$ at $37^{\circ} \mathrm{C}$. For cell apoptosis assays, cells were seeded in 48-well plates. After $24 \mathrm{~h}, 200 \mu \mathrm{l}$ of culture medium containing 5-FU, DMSO, inhibitors (Table 1) and exosomes was added to each well. Cells were then harvested for FACS analysis at different time points.

\section{Exosome isolation and normalization}

Exosomes were extracted from the same volume of culture medium without FBS. The supernatant was centrifuged at $300 \mathrm{~g}$ for $10 \mathrm{~min}$ at $4{ }^{\circ} \mathrm{C}$ and then at $1,000 \mathrm{~g}$ for $10 \mathrm{~min}$ at $4{ }^{\circ} \mathrm{C}$ to remove apoptotic bodies, followed by $10,000 \mathrm{~g}$ for $30 \mathrm{~min}$ at $4{ }^{\circ} \mathrm{C}$. Finally, the supernatant from the former step was centrifuged by $100,000 \mathrm{~g}$ for $70 \mathrm{~min}$ at $4{ }^{\circ} \mathrm{C}$ using an ultracentrifuge (Beckman Coulter, USA). After centrifugation, the exosomes were resuspended in complete culture medium or phosphate-buffered saline (PBS). Exo/P or Exo/R came from $10^{6} \mathrm{RKO} / \mathrm{P}$ or RKO/R cells was added to each well of 48 -well plates.

\section{Flow cytometry}

Apoptosis assays were performed after $72 \mathrm{~h}$, and the cells were harvested according to the manufacturer's instructions using an Annexin V-APC/7-AAD staining kit (MultiSciences, China). The apoptotic rate of the cells was determined by flow cytometry (BD FACSCanto, USA). All data were exported as FCS 3.0 documents and analyzed with FlowJo software 10.0.7. Cell cycle assays were performed after $24 \mathrm{~h}$, and cells were harvested according to the manufacturer's instructions for the cell cycle staining buffer (MultiSciences, China).

\section{BrdU proliferation assay}

Cells were plated in 96-well plates and incubated for $24 \mathrm{~h}$. Then, BrdU, 5-FU and exosomes were added to each well and incubated for $24 \mathrm{~h}$. Cell proliferation was measured using a BrdU cell proliferation ELISA kit (Abcam, UK). The absorbance of the samples was measured according to the manufacturer's instructions.

\section{Transmission electron microscopy (TEM)}

Exosomes were resuspended in PBS and placed onto copper grids at room temperature. Extra solution was removed with filter paper, and phosphotungstic acid solution was added. Then, filter paper was used again to remove the excess solution. The copper grids were dried at room temperature for $2 \mathrm{~min}$, and the exosomes

Table 1 Reagents list

\begin{tabular}{lll}
\hline Reagents & Product number & Company \\
\hline 5-fluorouracil & F8423-5G & Sigma-Aldrich (USA) \\
DMSO & D2650 & Sigma-Aldrich (USA) \\
ezatiostat & A8225 & APExBIO Technology (USA) \\
stattic & A2224 & APExBIO Technology (USA) \\
\hline
\end{tabular}


were observed with transmission electron microscopy (JEM-1200EX, Japan).

\section{High sensitivity flow cytometry (HSFCM)}

To determine size distribution, exosomes were resuspended with PBS after ultracentrifugation and detected with a Flow NanoAnalyzer (NanoFCM, China).

\section{Silver staining and shotgun proteomics}

Exosomes were lysed with SDT buffer (4\% SDS, $100 \mathrm{mM}$ DTT, $150 \mathrm{mM}$ Tris- $\mathrm{HCl}$ ) and boiled for $5 \mathrm{~min}$. The same volume of each sample was loaded. Exo/P and Exo/R proteins were visualized using a silver staining kit (Beyotime, China). Exo/R were lysed with SDT buffer and boiled for $15 \mathrm{~min}$ for mass spectrometry. Then, detergent, DTT and other low-molecular-weight components were removed, and the protein suspensions were digested at $37^{\circ} \mathrm{C}$ overnight. The resulting peptides were desalted on C18 cartridges (Sigma, USA). Mass spectrometry was performed on a $\mathrm{Q}$ Exactive mass spectrometer (Thermo Scientific, USA). Finally, the data were analyzed with MaxQuant software version 1.5.3.17 (Max Planck Institute of Biochemistry, Germany) and searched against the UniProt database.

\section{RNA-sequencing}

Total RNA was extracted from RKO/P and RKO/R. RNA molecules were purified using oligo $(\mathrm{dT})$ attached magnetic beads. Then, mRNA was fragmented into small pieces using fragmentation reagent. For cDNA synthesis, first-strand cDNA was generated using random N6 primers, followed by second strand synthesis. PCR was used to amplify the cDNA fragments with adaptors from the previous step. The double stranded PCR products were heat separated, and the single strand circle RNA was formatted as the final library. RNA-seq libraries were sequenced using a BGISEQ-500 sequencer. Raw reads that contained the sequences of adaptor and lowquality reads were filtered before downstream analysis. Clean reads were mapped to reference genes using Bowtie2. Gene expression levels were quantified by the RSEM software package, and NOISeq software was used to screen differentially expressed genes.

\section{WB analysis}

Cells and exosomes extracts were lysed with RIPA buffer (Beyotime, China) containing protease inhibitor (KeyGEN Biotech, China). Equal amounts of protein samples were loaded and run on SDS-PAGE gels equally and transferred to Hybridization Nitrocellulose Filter (Merck Millipore, Germany). Then, the membranes were blocked with 5\% skim milk (BD Biosciences, USA) dissolved in $0.1 \%$ Tris-buffered saline with Tween-20 (0.1\% TBST) at room temperature for $1 \mathrm{~h}$.
Next, the membranes were incubated with primary antibodies (Table 2) diluted in primary antibody solution (Toyobo, Japan) overnight at $4{ }^{\circ} \mathrm{C}$. On the following day, 0.1\% TBST was used to wash the membranes. Then, the membranes were incubated with secondary antibodies diluted at 1:5000 in $0.1 \%$ TBST at room temperature for $2 \mathrm{~h}$. HRP-conjugated goat anti-rabbit IgG $(\mathrm{H}+\mathrm{L})$ (Thermo Scientific, USA) and goat anti-mouse IgG $(\mathrm{H}+\mathrm{L})$ (Thermo Scientific, USA) were used for the secondary antibodies. Signals were developed with ECL (Santa Cruz, USA) and protein bands were visualized on $\mathrm{X}$-ray film.

\section{Confocal microscopy analysis}

$\mathrm{RKO} / \mathrm{P}$ cells were cultured in confocal dishes (NEST, China). Exo/P and Exo/R were labeled with the fluorescent dye PKH-26 (Sigma, USA) following the manufacturer's instructions. Then, exosomes were ultracentrifuged again. $\mathrm{RKO} / \mathrm{P}$ cells were incubated with the PKH-26 labeled Exo/ $\mathrm{P}$ and Exo/R. Cells were fixed with 4\% paraformaldehyde for $20 \mathrm{~min}$, and washed with PBS containing $0.1 \%$ Tween (0.1\% PBST) for confocal microscopy. Cell membranes were permeabilized with $0.2 \%$ Triton X-100 or methanol for $10 \mathrm{~min}$ and washed with $0.1 \%$ PBST. For immunofluorescence, cells were incubated with QuickBlock Blocking Buffer for Immunol Staining (Beyotime, China) for $1 \mathrm{~h}$ at room temperature and were then incubated with primary antibodies (Table 2) diluted in QuickBlock ${ }^{\text {ma }}$ Primary Antibody Dilution Buffer for Immunol Staining (Beyotime, China) at $4{ }^{\circ} \mathrm{C}$ in a humidified chamber overnight. Subsequently, the dishes were washed and incubated with anti-rabbit or antimouse Alexa Fluor ${ }^{\circ}$ Plus 488 secondary Antibody (1:500, Thermo Scientific, USA) at room temperature for $2 \mathrm{~h}$. Cell nuclei were labeled with DAPI (Thermo Scientific, USA) for $2 \mathrm{~min}$. Finally, the dishes were observed under a laser scanning confocal microscope (Leica TCS-SP8, Germany).

\section{Real-time cellular analysis (RTCA)}

RTCA (ACEA Biosciences, USA) was used to monitor cell viability, and was performed according to the manufacturer's instructions. Cell index is used to monitor cell status including cell numbers and cell attachment. When cells adhere to the surface of E-plate and influence the electrical impedance across the array, the xCELLigence software records electrical values and converts it into cell index [21]. First, $50 \mu \mathrm{l}$ of culture medium was added to measure the background value. Then, the cells were mixed with $50 \mu \mathrm{l}$ of culture medium and seeded into E-plates. Culture medium containing exosomes, 5-FU, DMSO and inhibitors was added when the cell index reached 1.0. The data were documented and exported with ACEA 
Table 2 Primary antibody list

\begin{tabular}{llll}
\hline Name & Product number & Company & Dilution (WB) \\
\hline ALIX & GTX42812 & Genetex (USA) & $1: 200$ \\
Caspase-9 & 9502 & Cell Signaling Technology (USA) & $1: 1000$ \\
Caspase-3 & 9662 & Cell Signaling Technology (USA) & $1: 1000$ \\
CD63 & ab59479 & Abcam (UK) & $1: 200$ \\
CD9 & ab92726 & Abcam (UK) & $1: 200$ \\
GAPDH & $10494-1$-AP & Proteintech (USA) & $1: 1000$ \\
GSTP1 & GTX112695 & Genetex (USA) & $1: 1000$ \\
LaminB1 & $12987-1$-AP & Proteintech (USA) & $1: 1000$ \\
p-STAT3 (Tyr705) & 9145 & Cell Signaling Technology (USA) & $1: 200$ \\
STAT3 & 9139 & Cell Signaling Technology (USA) & $1: 1000$ \\
TBP & 44059 & Cell Signaling Technology (USA) & $1: 1000$ \\
TSG101 & ab125011 & Abcam (UK) & $1: 200$ \\
$\beta$-actin & $60008-1-$ Ig & Proteintech (USA) & $1: 1000$ \\
\hline
\end{tabular}

Biosciences RTCA software 2.0 and analyzed by Microsoft Excel and GraphPad Prism 7.0.

\section{siRNA transfection}

Chemically synthesized GSTP1 and STAT3 siRNAs (Table 3) and control siRNAs were purchased from RiboBio (China). The sequences of the siRNAs are shown in Table 3. The siRNAs were transiently transfected into RKO/P and RKO/R cells using Lipofectamine RNAiMAX (Invitrogen, USA) according to the manufacturer's instructions. After $48 \mathrm{~h}$ of transfection, the cells were analyzed by $\mathrm{WB}$, and the conditional medium was collected.

\section{Caspase-3 activity assay}

Cells were seeded in 96-well plates, and culture medium containing exosomes, 5-FU, DMSO and inhibitors were added after $24 \mathrm{~h}$. Caspase- 3 activity was determined per well according to the manufacturer's instructions for the GreenNuc ${ }^{\mathrm{Tn}}$ Caspase-3 activity assay kit (Beyotime, China). Fluorescence images were obtained using an Operetta CLS ${ }^{\mathrm{TM}}$ high-content cell imaging analysis system (PerkinElmer, USA), and a $20 \times$ objective lens was used in our experiment. The percentage of caspase- 3 was calculated by the software Harmony 4.5 and GraphPad Prism 7.0.

Table 3 siRNA sequences

\begin{tabular}{lll}
\hline Gene & & Sequence \\
\hline GSTP1 & si-1 & CCTACACCGTGGTCTATTT \\
& si-2 & TACATCTCCCTCATCTACA \\
STAT3 & si-1 & CCGTGGAACCATACACAAA \\
& si-2 & CATCTGCCTAGATCGGCTA \\
\hline
\end{tabular}

\section{Animal experiments}

Animal experiments were approved by the Committee on the Ethics of Animal Experiments of The Sixth Affiliated Hospital, Sun Yat-sen University. Male BALB/c nude mice (4-5 weeks) were purchased from Charles river (China). $\mathrm{RKO} / \mathrm{P}$ cells were injected to the right flank of each mouse subcutaneously $\left(3 \times 10^{6}\right.$ cells in $200 \mu \mathrm{l}$ PBS per mouse). All mice were divided into four groups (Exo/P + DMSO, Exo/P + stattic, Exo/R + DMSO, Exo/R + stattic) when tumors reached volume of $50-100$ $\mathrm{mm}^{3} .5$-FU $(50 \mathrm{mg} / \mathrm{kg})$ and stattic $(25 \mathrm{mg} / \mathrm{kg})$ were administered intraperitoneally (i.p.) every 2 days. Exosomes $(10 \mu \mathrm{g})$ were injected into the xenograft tumors every 4 days. Tumor volumes and body weights were measured every 2 days. The mice were sacrificed after 17 days of treatment, and the size and weight of tumors from each group were measured.

\section{Statistical analysis}

Statistical analysis was performed with the GraphPad Prism 7 software. All data were presented for two replicates or three times. Statistical significance was determined by Student's t-test for two groups. We also used One-way ANOVA multiple comparison analysis with Tukey's posttest. Two-way ANOVA with Fisher's LSD test was used to compare more groups. $P<0.05$ was regarded as statistically significant.

\section{Results}

Exosomes from RKO/R cells attenuated the chemosensitivity of 5-FU-sensitive cells

Studying the mechanisms of chemotherapy resistance remains a challenge due to tumor heterogeneity and the complex tumor microenvironment. We interpreted it in colorectal cancer cells utilizing 5-FU resistant cells 
(RKO/R) established from 5-FU sensitive cells (RKO/P). To determine the capability of exosomes isolated from $\mathrm{RKO} / \mathrm{R}$ cells to transmit acquired 5-FU resistance to recipient cells, we first cultured recipient cells $(\mathrm{RKO} / \mathrm{P}$ and HCT116) in medium containing 5-FU plus Exo/P or Exo/ R. After $72 \mathrm{~h}$, we observed the cells under a microscope and found that there were more survival cells attached the plate upon treatment with Exo/R and 5-FU (Fig. 1a). To analyze this change, we used RTCA to monitor cell viability continuously. The results showed that the cell index of the recipient cells incubated with Exo/R was significantly higher than that of the recipient cells incubated with Exo/P (Fig. 1b, c). To determine whether the cell index was altered by reduced cell death or increased cell proliferation, we next measured cell proliferation and cell apoptosis in the recipient cells. Notably, although the cell cycle was significantly arrested by $5-\mathrm{FU}, \mathrm{Exo} / \mathrm{R}$ did not alter the cell cycle distribution significantly

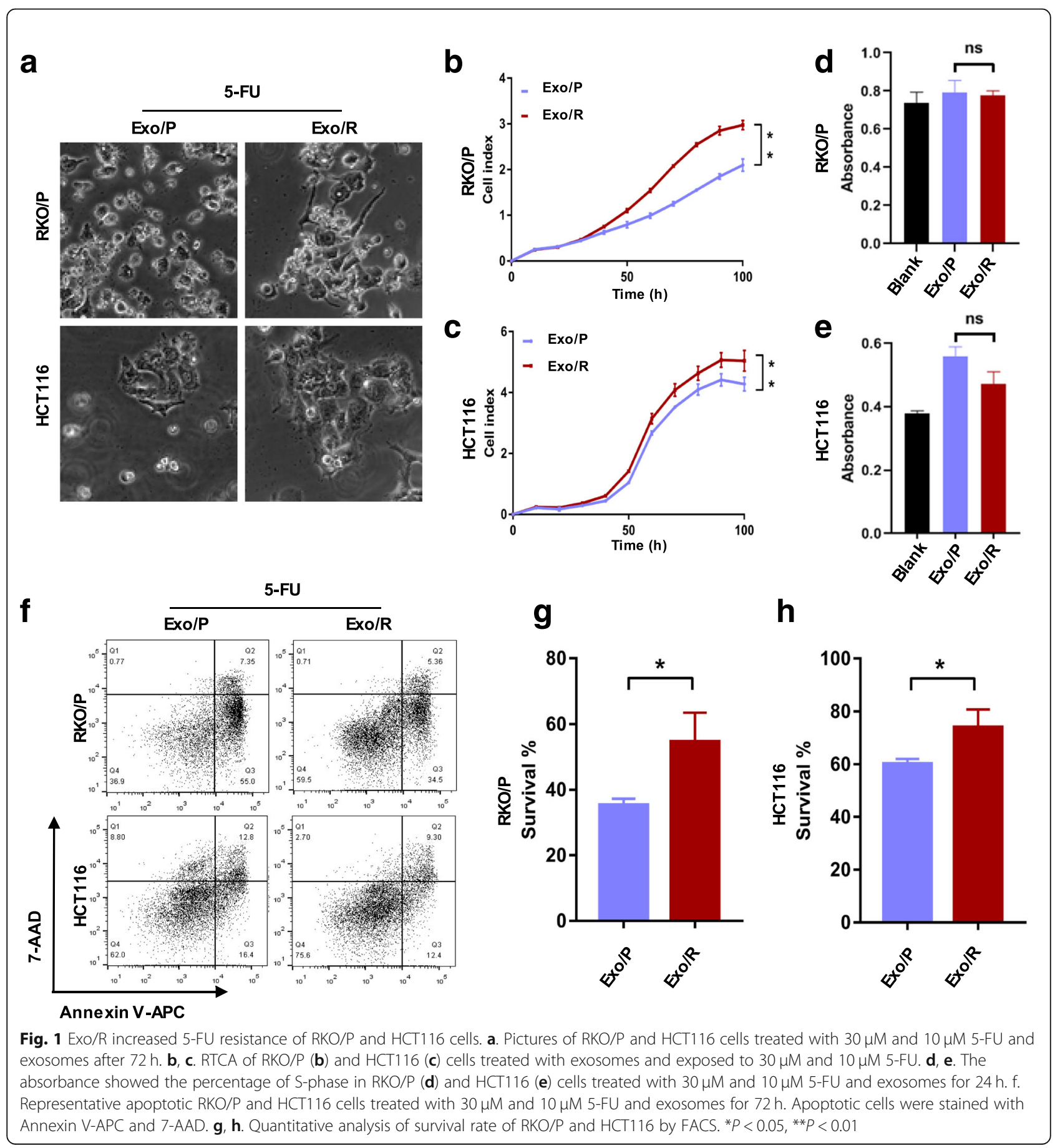


(see Additional file 1: Figure S1). To further interpret cell proliferation in recipient cells, BrdU was used to measure cell cycle blockade at S-phase. Exo/R did not alter S-phase arrest induced by $5-\mathrm{FU}$ in $\mathrm{RKO} / \mathrm{P}$ and HCT116 cells importantly (Fig. 1d, e). However, the cell apoptosis assay results indicated that Exo/R significantly promoted cell survival compared to Exo/P (Fig. 1f, g, h). Thus, we proved that exosomes from resistant cells were responsible for acquired 5-FU resistance by decreasing apoptosis in recipient cells. a

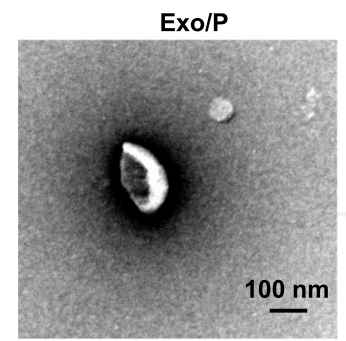

C

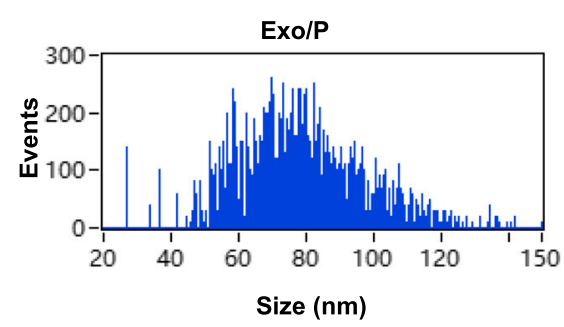

d

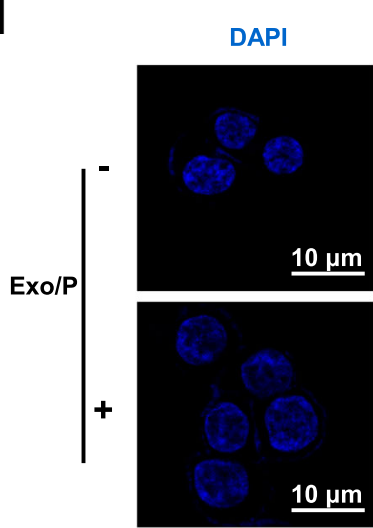

PKH-26 labeled
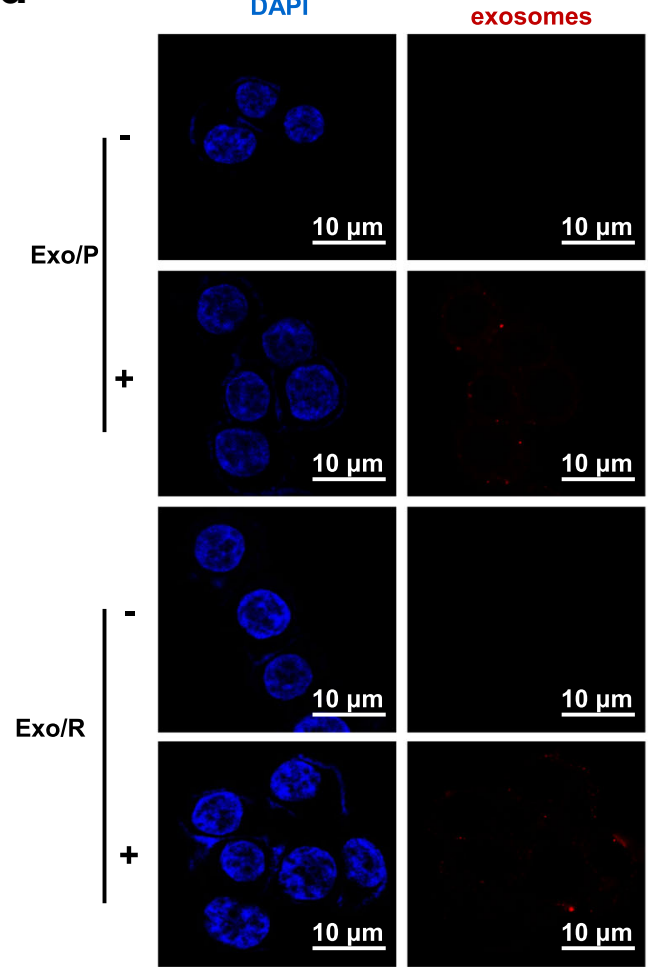

Exo/R

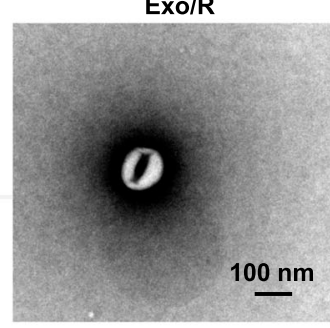

b
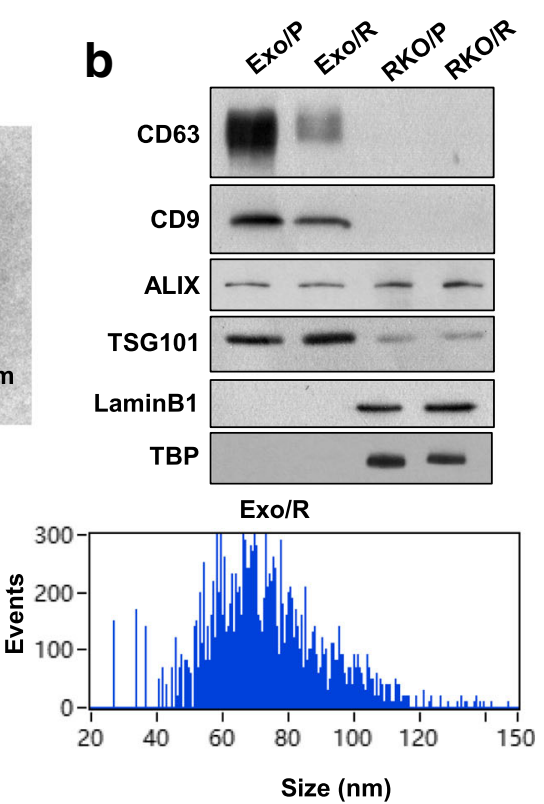

Bright
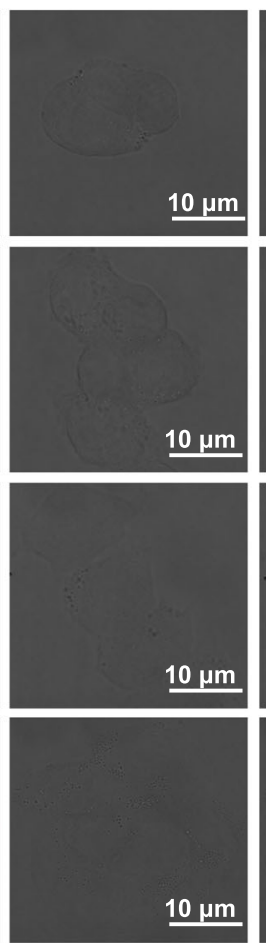

Merge
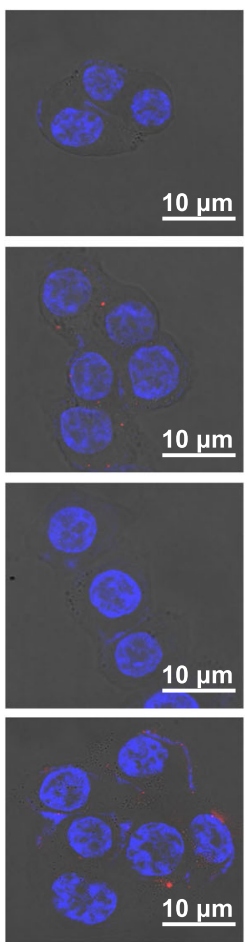

Fig. 2 The identification of exosomes and uptake of exosomes by RKO/P cells. a. Representative images of exosomes derived from RKO/P and RKO/R taken by TEM (scale bar, 100 nm). b. Exosomal markers (CD63, CD9, ALIX, TSG101) and non-exosomal makers (LaminB1, TBP) were analyzed by WB in EXO/P, EXO/R, RKO/P and RKO/R. c. Histogram indicated diameter of exosomes purified from RKO/P and RKO/R analyzed by HSFCM. $\mathbf{d}$. Confocal images of cells incubated with (+) or without (-) PKH-26 labelled Exo/P and Exo/R for $6 \mathrm{~h}$. (scale bar, $10 \mu \mathrm{m}$ ) 
The characteristics of Exo/P and Exo/R

As Exo/P and Exo/R showed different abilities to induce 5-FU resistance, we hypothesized that their characteristics were different. Exosomes were isolated from an equal volume of conditional medium collected from $\mathrm{RKO} / \mathrm{P}$ and $\mathrm{RKO} / \mathrm{R}$ cells and characterized by TEM, WB and HSFCM. As expected, typical cup-shaped morphology and similar size distribution were confirmed in both Exo/P and Exo/R (Fig. 2a, c). In addition, the exosomal markers CD63, CD9 and ALIX were enriched in Exo/P and Exo/R while TSG101 was detected in both cells and exosomes. Moreover, the absence of the

\section{a}

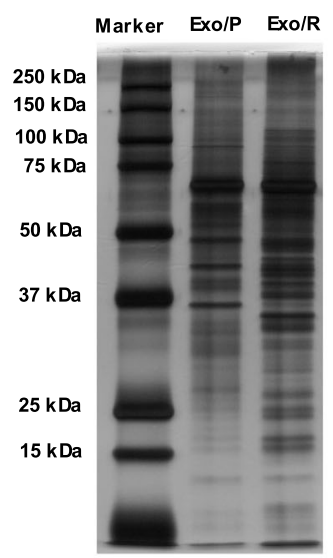

C

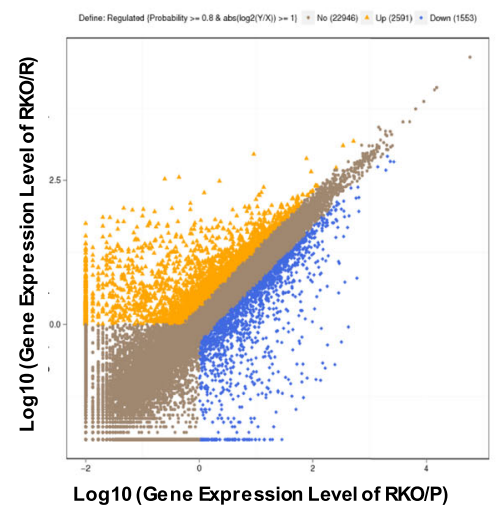

d

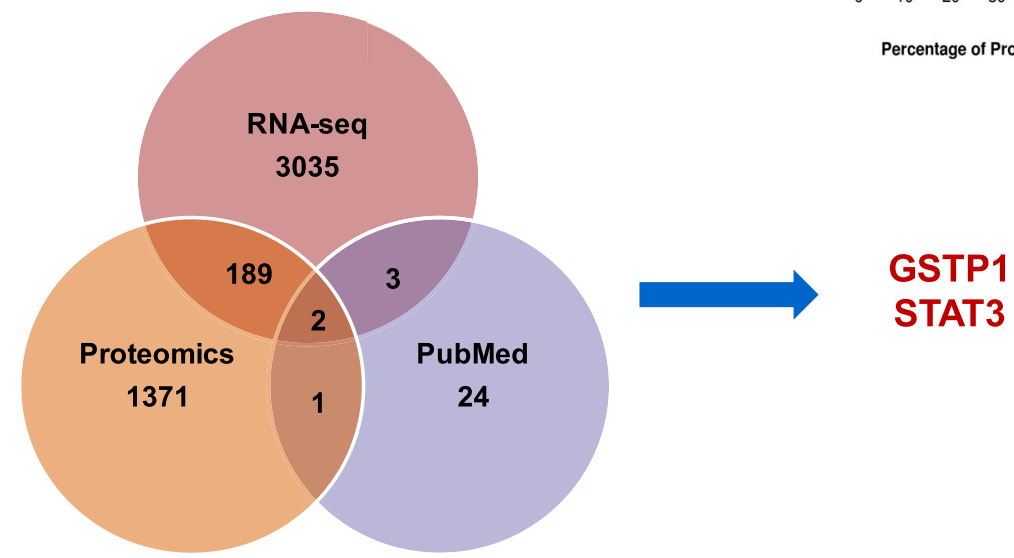

b biological regulation
cellular component organization or biogenesis
detoxification rhythmini process
positive regulation of biological process
negative regulation of biological process regulation of biological process response to stimulus localization
multi-organism process catalytic activity
signal transducer activity signal transducer activity
structural molecule activity transporter activity
bing antioxidant activity translation regulator activity molecular transducer activity molecular function regulator hijacked molecular function transcription regulator activity membrane
extracellular region supramo synapse
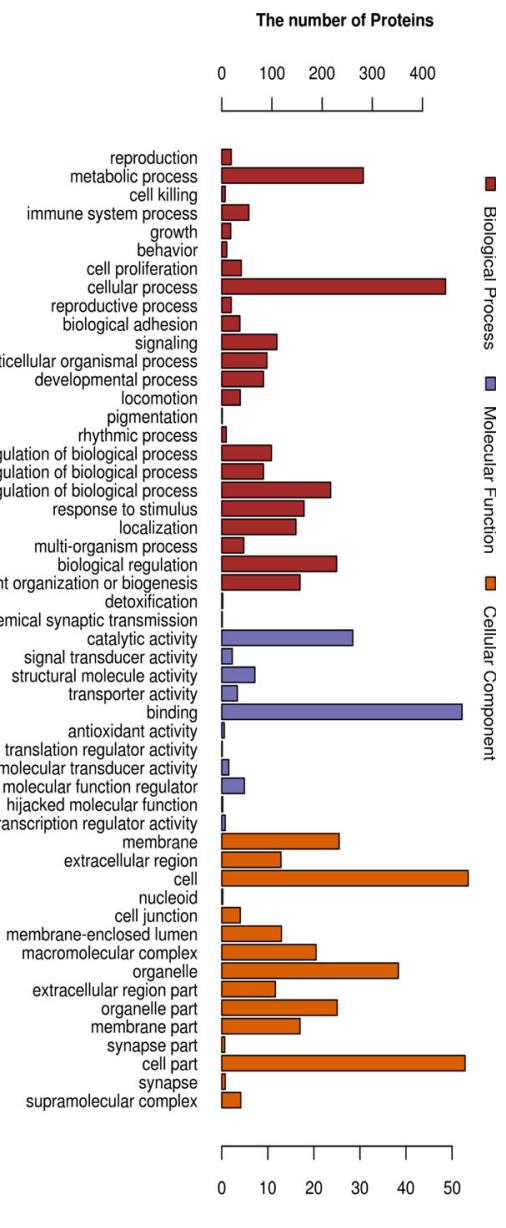

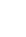

(n)

(1)

\section{(n)}

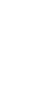


nuclear markers LaminB1 and TBP in Exo/P and Exo/R indicated the purity of the exosomes in our experiment (Fig. 2b). We next examined whether these exosomes were taken up by recipient cells. Purified Exo/P and Exo/R were labeled with PKH-26 (red fluorescence) and incubated with recipient cells. After $6 \mathrm{~h}$, the localization of exosomes in cells was observed by confocal microscopy (Fig. 2d). Collectively, these results suggested that Exo/R mediated 5-FU resistance may be associated with exosome internalization.

\section{Identification of chemoresistant proteins in exosomes}

We hypothesized that the proteins encapsulated in exosomes are involved in 5-FU resistance. To validate this hypothesis, we utilized SDS-PAGE and silver staining to fractionate and detect the proteins in exosomes. Notably, the protein profile displayed abundant distinct protein bands for Exo/P and Exo/R (Fig. 3a). To further determine 5-FU resistance related exosomal proteins, shotgun proteomics analysis was performed on Exo/R. The raw data were processed using the human Uniprot database and 964 proteins were identified in Exo/R. Next, bioinformatic tools were used to characterize the function of proteins in Exo/R. A total of 918 proteins were analyzed for gene ontology (GO) annotation and predicted to be involved in the biological processes, molecular functions and cellular components (Fig. 3b). To identify the key proteins involved in exosome-mediated 5FU resistance, RNA-sequencing was performed on RNA samples extracted from $\mathrm{RKO} / \mathrm{P}$ and $\mathrm{RKO} / \mathrm{R}$ and differentially expressed RNAs were plotted (Fig. 3c). After combining the results of 964 identified proteins and 3229 upregulated RNAs (probability>0.69), 192 gene symbols were screened (Additional file 2: Table S1). Among these results, we searched for reported chemoresistance associated proteins and selected GSTP1 and STAT3 for further study (Fig. 3d).

GSTP1 and p-STAT3 are nuclear proteins enriched in Exo/R To validate whether GSTP1 and STAT3 were enriched in Exo/R, we lysed Exo/P and Exo/R. Compared with that in Exo/P, increased expression of GSTP1 but not STAT3 was detected in Exo/R. Notably, we also detected p-STAT3 in Exo/R, which could not be detected in Exo/

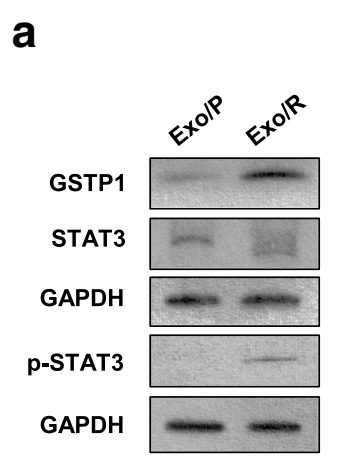

b
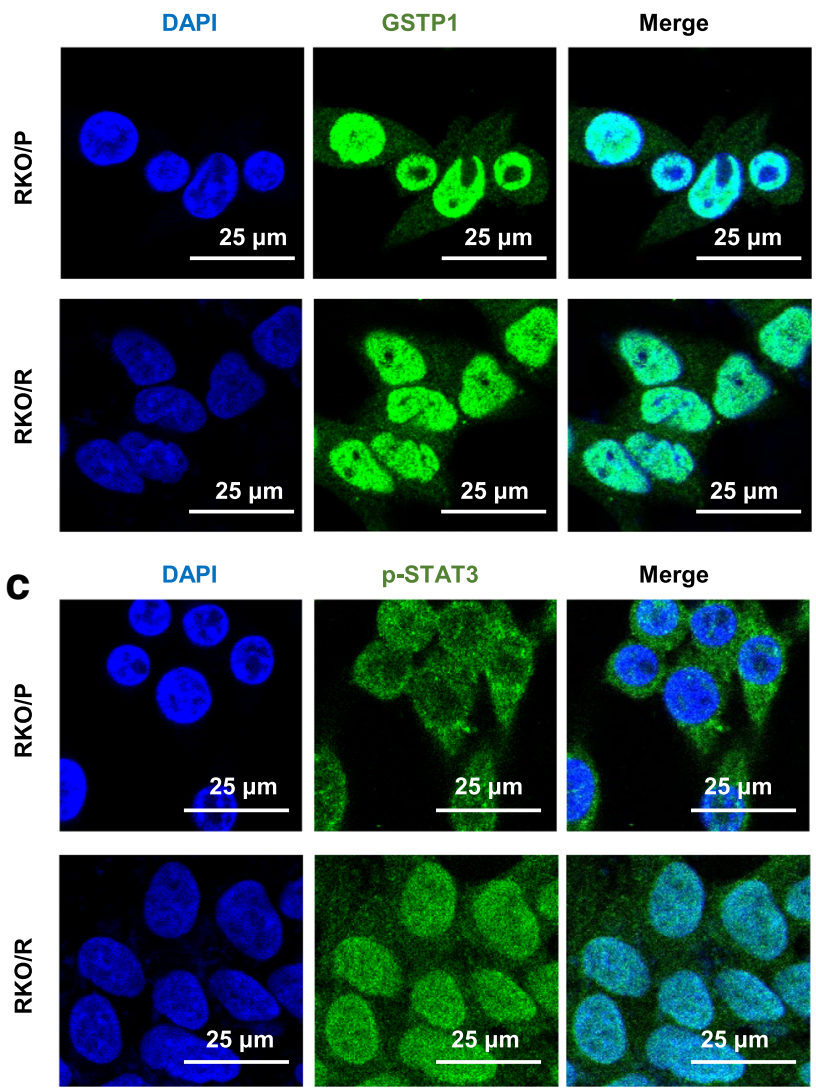

Fig. 4 The detection of GSTP1 and p-STAT3 in exosomes and cells. a. The detection of GSTP1, STAT3 and p-STAT3 in EXo/P and EXo/R. b, c. Immunofluorescence of GSTP1 and p-STAT3 in RKO/P and RKO/R. (scale bar, $25 \mu \mathrm{m}$ ) 
P (Fig. 4a). p-STAT3 and GSTP1 are known to be located mainly in the cell nucleus. We next explored the distribution of GSTP1 and p-STAT3 in RKO/P and $\mathrm{RKO} / \mathrm{R}$ cells. Immunofluorescence showed that GSTP1 was expressed mainly in cell nucleus and partially expressed in the cytoplasm of RKO/P and RKO/R cells (Fig. 4b). p-STAT3 was expressed in both the nucleus and cytoplasm of $\mathrm{RKO} / \mathrm{R}$ cells but not in the nucleus of $\mathrm{RKO} / \mathrm{P}$ cells (Fig. 4c). These observations suggested that GSTP1 and p-STAT3 are enriched in Exo/R and may be responsible for exosome-mediated 5-FU resistance.
P-STAT3 is required for exosome-mediated 5-FU resistance To further investigate whether exosomal GSTP1 or p-STAT3 is involved in acquired 5-FU resistance, we used protein inhibitors in combination with exosomes to treat recipient cells. We first evaluated the effect of exosomal GSTP1 in mediating 5-FU resistance. The results showed that neither the morphology nor the survival rate of cells treated with Exo/R and a GSTP1 inhibitor (ezatiostat) changed significantly compared to those of cells treated with Exo/R and DMSO (Fig. 5a, b, c), excluding the possibility that 5-FU resistance is mediated by GSTP1 in exosomes. Moreover, a

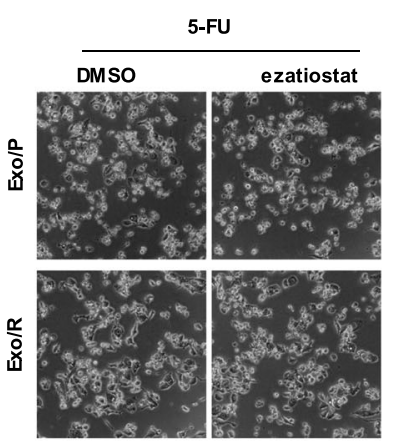

d

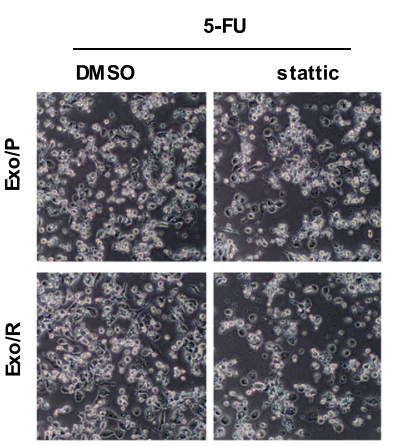

g

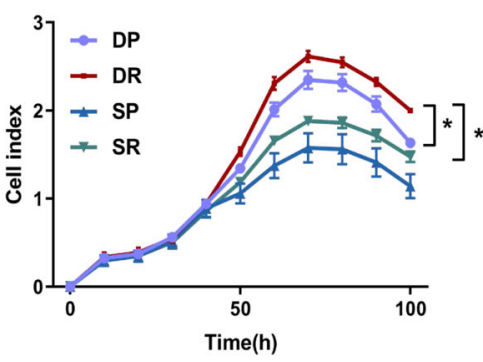

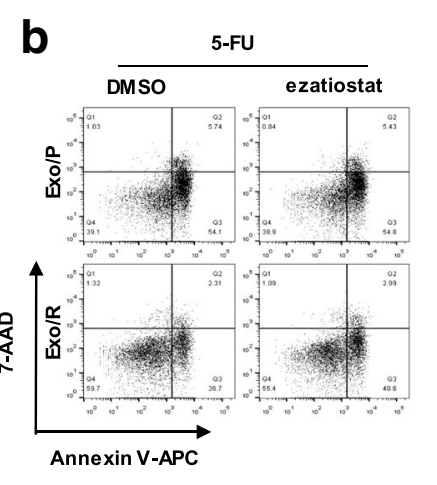

$\mathbf{e}$

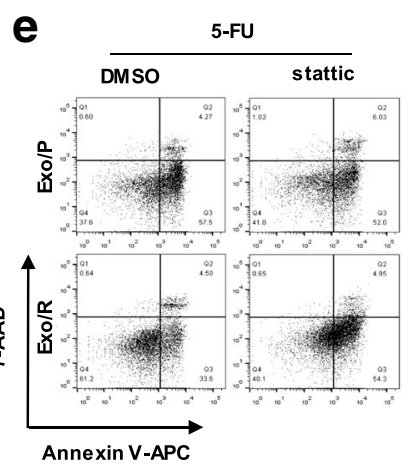

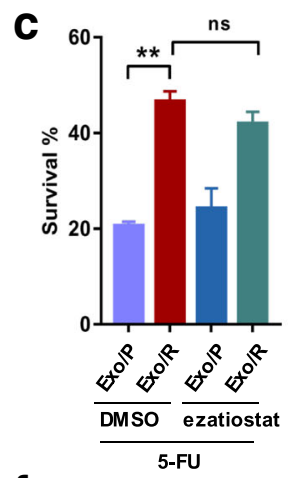

f

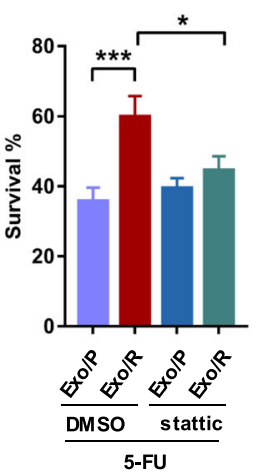

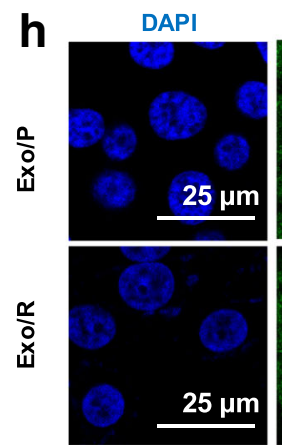
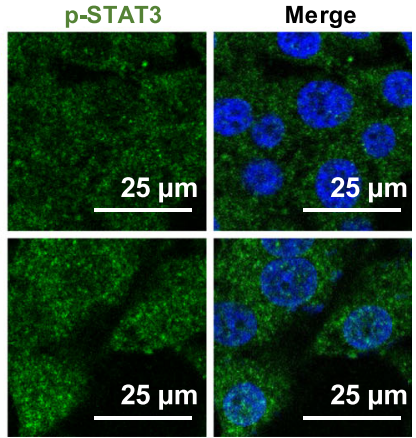

Fig. 5 The verification of p-STAT3 transferred by ExO/R and its anti-apoptotic function in RKO/P cells. $\mathbf{a}, \mathbf{b}$, $\mathbf{c}$. Representative images of RKO/P treated with $30 \mu \mathrm{M}$ 5-FU, $10 \mu \mathrm{M}$ ezatiostat and exosomes for $72 \mathrm{~h}$ and statistical analysis of the survival rate. $\mathbf{d}$, e, $\mathbf{f}$. Representative images of RKO/ $\mathrm{P}$ cells treated with $30 \mu \mathrm{M}$ 5-FU, $7.5 \mu \mathrm{M}$ stattic and exosomes for $72 \mathrm{~h}$ and statistical analysis of the survival rate. g. RTCA analysis of cell index of $\mathrm{RKO} / \mathrm{P}$ cells treated with $30 \mu \mathrm{M}$ 5-FU, Exo/P and Exo/R, DMSO or $5 \mu \mathrm{M}$ stattic. DP: DMSO + Exo/P, DR: DMSO + Exo/R, SP: stattic + Exo/P, SR: stattic + Exo/R. h. Confocal images of p-STAT3 in RKO/P cells co-cultured with Exo/P or Exo/R in the absence of 5-FU. (scale bar, $25 \mu \mathrm{m}$ ) ${ }^{*} P<0.05,{ }^{* *} P<0.01,{ }^{* *} P<0.001$ 
both apoptotic morphology and reduced cell survival demonstrated that a STAT3 inhibitor (stattic) abolished 5-FU resistance induced by Exo/R (Fig. 5d, e, f). The effect of exosomal GSTP1 and p-STAT3 in mediating acquired 5FU resistance was also verified by siRNA. Down-regulating p-STAT3 in RKO/R cells markedly abolished the antiapoptotic function of Exo/R (Additional file 1: Figure S2). A significant decrease in the cell index also supported the effect of exosomal p-STAT3 on 5-FU resistance (Fig. 5g). Furthermore, immunofluorescence was carried out to stain p-STAT3 in recipient cells. We co-cultured Exo/P or Exo/R with recipient cells for $72 \mathrm{~h}$ and found that more $\mathrm{p}-$ STAT3 was expressed in the cell nucleus (Fig. 5h). Taken together, these results showed that p-STAT3 transfer via exosomes is responsible for acquired 5-FU resistance, and that p-STAT3 inhibition can restore the sensitivity of recipient cells to 5-FU.

\section{The caspase pathway is responsible for p-STAT3-mediated} 5-FU resistance

To clarify the molecular mechanisms by which exosomes contribute to 5-FU resistance in CRC, we investigated the caspase cascade in recipient cells. We first confirmed that p-STAT3 was increased in cells treated with Exo/R by WB. In addition, less cleaved caspase- 9 and caspase-3 expression demonstrated that Exo/R decreased cell apoptosis when exposed to 5-FU (Fig. 6a). To demonstrate that stattic overcomes Exo/R-mediated 5-FU resistance, we assessed caspase-3 activity in RKO/ $\mathrm{P}$ cells. The results showed that activated caspase- 3 increased after exposure to stattic for $36 \mathrm{~h}$ and $72 \mathrm{~h}$ compared to that after DMSO exposure (Fig. 6b, c). Consistent with this finding, the apoptosis-related proteins caspase-9, caspase-3, and PARP were also determined in recipient cells using WB. Cleaved caspase-9 increased obviously after treatment with stattic. Cleaved caspase-3 and PARP were also detected by WB (Fig. 6d). These data highlighted the role of the caspase cascade in 5-FU resistance mediated via exosomal p-STAT3.

\section{Exosomes from RKO/R cells induce 5 -FU resistance in $\mathrm{RKO} / \mathrm{P}$ cells in vivo}

To further determine whether exosomal p-STAT3 can induce 5-FU resistance in colorectal cancer in vivo, we established a subcutaneous xenograft model in BALB/c nude mice with $\mathrm{RKO} / \mathrm{P}$ cells. 5-FU was injected into each group together with exosomes (Exo/P or Exo/R) and stattic or DMSO (Fig. 7a). The sizes of subcutaneous tumors treated with Exo/R were larger than those treated with Exo/P under 5-FU therapy, indicating that Exo/R inhibited the effect of 5-FU and promoted tumor

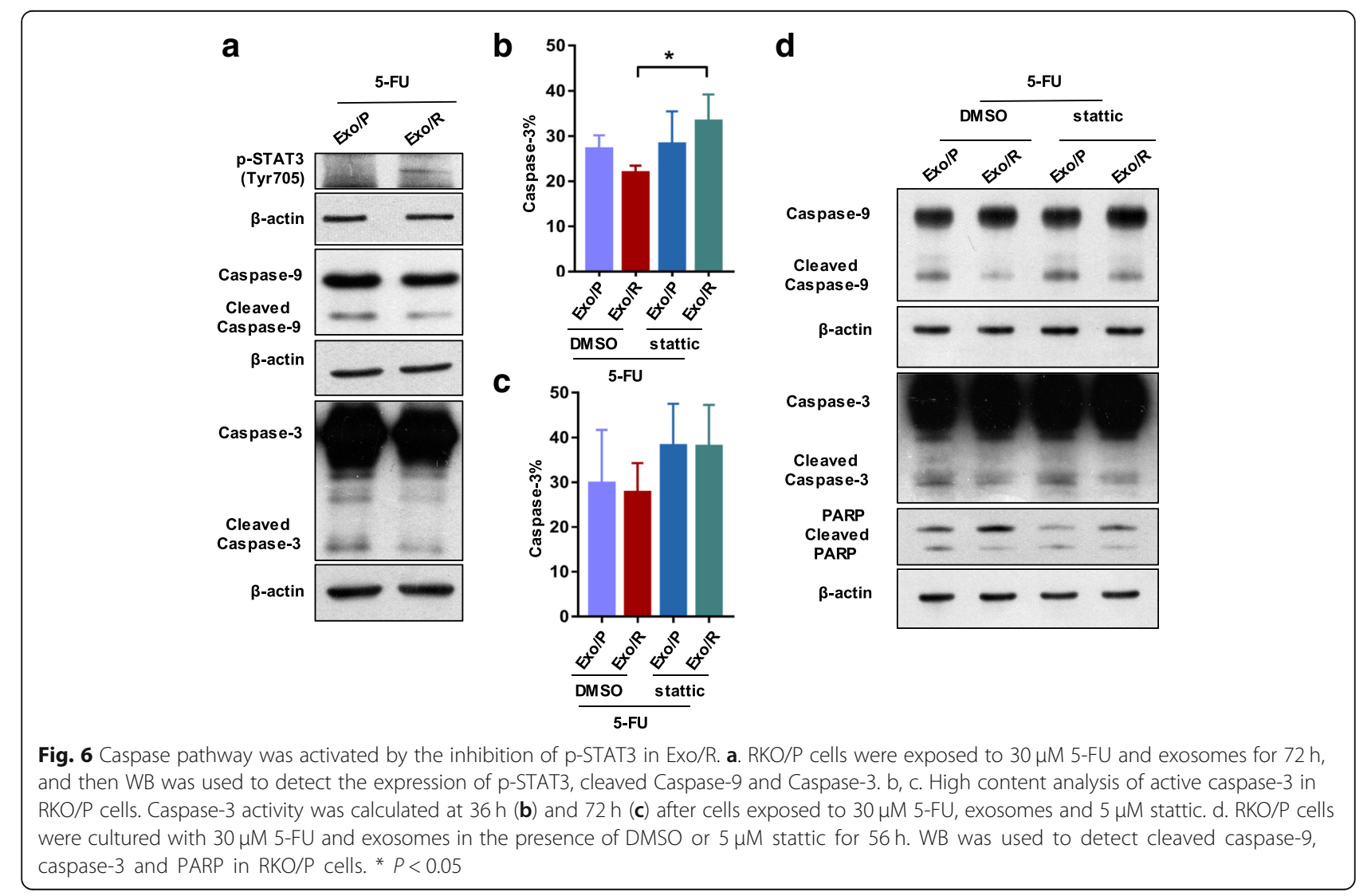




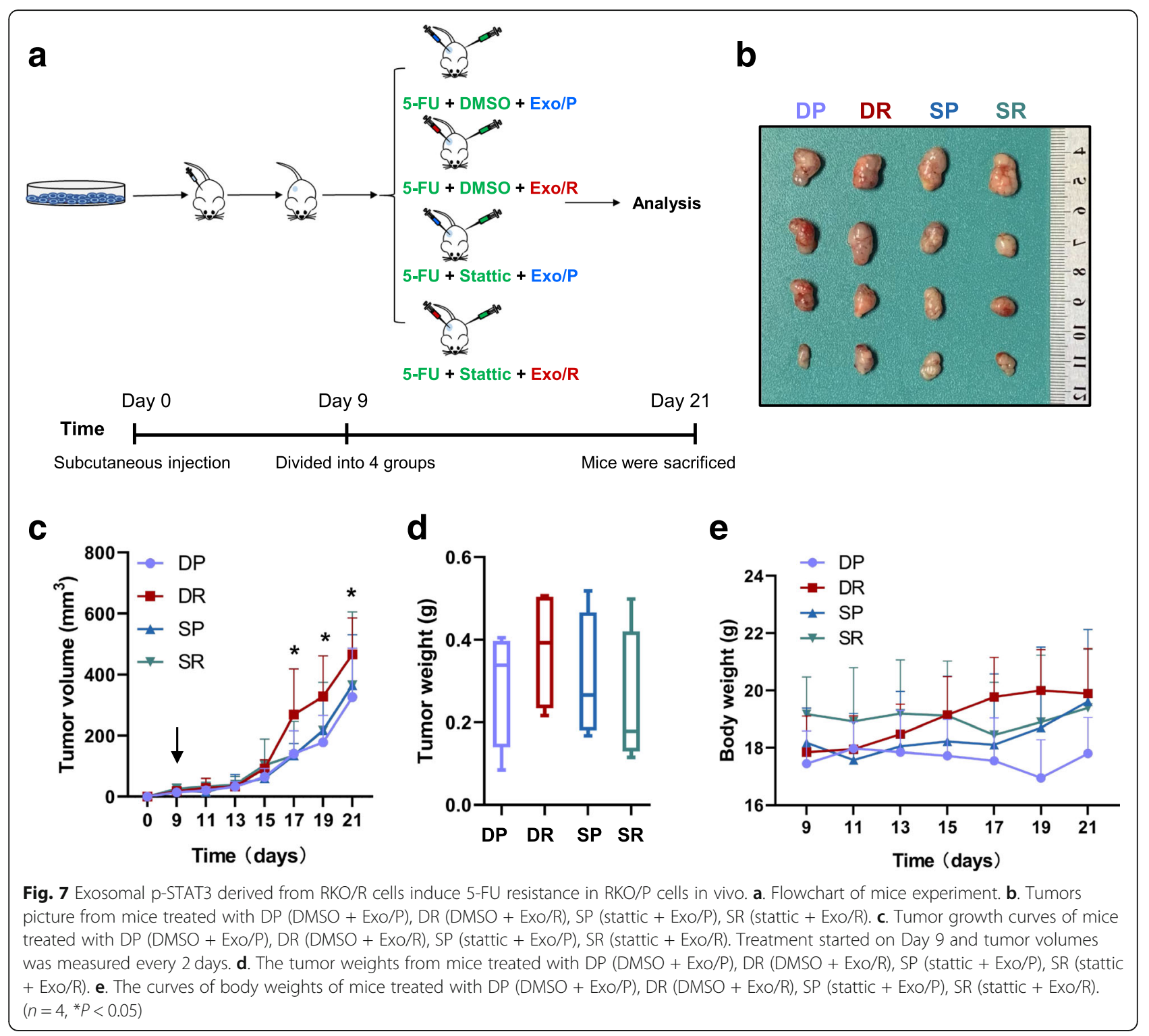

growth. In addition, the volumes of tumors treated with Exo/R plus stattic were not different from those of tumors treated with Exo/P, but were smaller than those treated with Exo/R plus DMSO (Fig. 7b, c). Furthermore, the mean tumor weights of mice treated with Exo/R were heavier than those of mice in other groups (Fig. 7d). The body weights of mice treated with Exo/R were a little heavier than other groups (Fig. 7e). Taken together, these results indicated the function of $\mathrm{p}$ STAT3 encapsulated by Exo/R in regulating 5-FU resistance in colorectal cancer cells in vivo.

\section{Discussion}

5-FU-based chemotherapy significantly prolonged the life expectancy of patients, however, resistance to 5FU is a major limitation to treatment success [22].
Due to complicated and variable biological processes, the mechanisms of chemoresistance are still elusive [23]. It is known that the functions of exosomes are not restricted to maintaining normal biological processes but also encompass drug resistance. Previous studies have shown that exosomes secreted by bone marrow stromal cells (BMSCs), CAFs and tumor cells promote chemotherapy resistance in human tumors [24-26]. In this study, we isolated exosomes from 5FU-resistant cells, identified exosomal p-STAT3 with shotgun proteomics analysis and verified its function in 5-FU resistance. These findings demonstrated an unconventional mechanism of acquired drug resistance in colorectal cancer.

Exosomes play multiple roles in intercellular communication by transmitting RNAs and proteins $[27,28]$. In 
previous studies, exosomes were described as important vesicles disseminating drug resistance. MicroRNAs in exosomes, which could change various pathways related to chemotherapy resistance have been reported in different cancers. For instance, cisplatin resistance in lung cancer is associated with exosomal miR-100-5p [29], and the PI3K/Akt pathway in hepatocellular carcinoma (HCC) is activated by miR-32-5p delivered by exosomes from resistant cells [30]. Efflux of the tumor-suppressors miR-145 and miR-34a via microvesicles is responsible for 5-FU resistance in colon cancer cells [31]. Notably, the transmission of proteins by exosomes is significant in regulating chemotherapy resistance. For instance, some researchers have shown that TrpC-5-containing extracellular vesicles in breast cancer and P-glycoprotein (P-gp)-containing microvesicles in ovarian cancer are responsible for chemotherapeutic resistance [32, 33]. GSTP1, which is associated with detoxification and glutathione conjugation, has been reported in adriamycinresistant breast cancer cells [34, 35]. However, in the above studies, the functional proteins were selected by subjective conjecture instead of screening objectively. Thus, only some well-known proteins were identified and novel and pivotal components in the exosomes were not explored. In contrast, we performed proteome profiling analysis and subsequent validation studies. Our results demonstrated for the first time that p-STAT3 accumulation in exosomes is relevant to 5-FU resistance. More importantly, the results suggested that more large-scale mass spectrum-based analyses should be performed to screen potential chemoresistant proteins in exosomes.

Previous study has found that IL-6 could induce STAT3 phosphorylation and subsequently regulate transcription [36]. STAT3 is activated in many cancers and associates with patient's survival [37]. In addition, increased p-STAT3 levels have been reported in CRC and correlated with chemoradiotherapy [38]. Recent studies revealed that the inhibition of STAT3 sensitized colorectal cancer cells to 5-FU treatment through downregulating cyclinD1 [39]. Nevertheless, few studies have focused on exosomal p-STAT3 in colorectal cancer and the selectivity of proteins transported by exosomes has not been fully understood. A previous study indicated that cells treated with 5-FU were larger than control cells, and their nuclear staining was pale [40]. Our results showed that the nuclei of $\mathrm{RKO} / \mathrm{R}$ cells appeared irregular shape and had pale DAPI staining. In brief, our findings not only illustrated the enrichment of p-STAT3 in exosomes but also implied the possible mechanisms that regulate this enrichment in exosomes.

Stattic, which selectively inhibits the activation, dimerization and nuclear translocation of STAT3, was used to prevent p-STAT3 from translocating to the nucleus [41]. In our study, p-STAT3 was enriched in Exo/R and participated in exosome-mediated 5-FU resistance. These results suggested that developing inhibitors that selectively impair the function of $\mathrm{p}$ STAT3 would be an effective way to reduce exosomemediated chemotherapy resistance. Additionally, more evidence suggests that exosomes could be used as promising biomarkers to diagnose cancer [42]. However, their application in diagnosing chemotherapy resistance is still lacking. Thus, the application of p-STAT3 as a potential biomarker would help to monitor the 5-FU resistance of patients during treatment. More investigations are needed to validate the clinical use of p-STAT3-containing

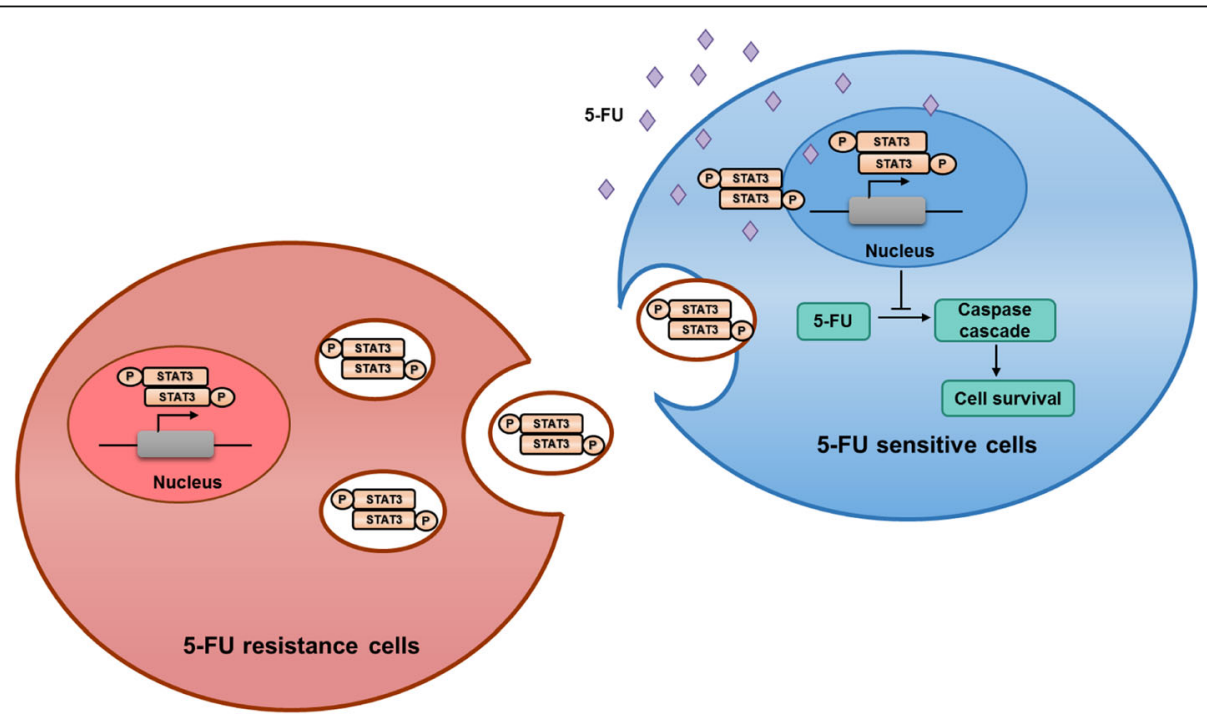

Fig. 8 Schematic representation of exosomal p-STAT3 in regulating 5-FU resistance. A schematic diagram indicated how exosomes from RKO/R cells mediated 5-FU resistance in sensitive cells 
exosomes as a therapeutic target and biomarker in colorectal cancer.

\section{Conclusions}

In summary, our findings prove that p-STAT3 transferred by exosomes from 5-FU-resistant cells could induce chemotherapy resistance in recipient cells by reducing caspase cascade activation (Fig. 8).

\section{Additional files}

Additional file 1: Figure S1. The cell cycle distribution of RKO/P and HCT116 cells. a. Representative cell cycle changes of HCT116 and RKO/P cells exposed to $10 \mu \mathrm{M}$ or $30 \mu \mathrm{M}$ 5-FU and Exo/P or Exo/R after 24 hours. The DNA content was stained with PI. exposed to $10 \mu \mathrm{M}$ or $30 \mu \mathrm{M}$ 5-FU and Exo/P or Exo/R after 24 hours. The DNA content was stained with PI. Figure S2. p-STAT3 transferred by Exo/R p-STAT3 transferred by Exo/R mediated acquired 5-FU resistance in RKO/P cells. $\mathbf{a}$. The WB result of GSTP1 and STAT3 in RKO/P and RKO/R cells transfected with si-NC, siGSTP1 (si-1, si-2) and si-STAT3 (si-1, si-2). b. Statistical analysis of the survival rate of RKO/P cells treated with $30 \mu \mathrm{M}$ 5-FU and exosomes from $\mathrm{RKO} / \mathrm{P}$ or RKO/R cells after down-regulation of GSTP1. c. Statistical analysis of the survival rate of RKO/P cells treated with $30 \mu \mathrm{M} 5$-FU and exosomes from RKO/P or RKO/R cells after down-regulation of $\mathrm{p}-\mathrm{STAT3} .{ }^{*} P<0.05$, **P $<$ 0.01. (PDF $308 \mathrm{~kb}$ )

Additional file 2: Table S1. Overlapped parts in Venn diagram among RNA-seq, Proteomics and PubMed. (DOCX $17 \mathrm{~kb}$ )

\section{Abbreviations}

5-FU: 5-fluorouracil; CRC: colorectal cancer; Exo/P: exosomes from RKO/P Exo/R: exosomes from RKO/R; HSFCM: high-sensitivity flow cytometer; RKO/ P: RKO parental cell line; RKO/R: 5-FU resistant cell line; RTCA: Real-Time Cellular Analysis; TEM: transmission electron microscopy; WB: western blotting

\section{Acknowledgements}

We thank Gregory Karran-Ali for his suggestion about the language of our manuscript.

\section{Authors' contributions}

QZ performed the experiments. RXL conceived the research. QZ and RXL analyzed the data. QZ wrote the manuscript and RXL revised the manuscript. KWC performed animal experiments. KWC and JH helped to revise the manuscript. JZ, LW and HT helped to perform experiments. XY provided the results of RNA-sequencing. HL revised the manuscript and supervised the study. All authors read the paper and approved the final manuscript.

\section{Funding}

This work was funded by National Natural Science Foundation of China (81772573, 81672413); National Postdoctoral Program for Innovative Talents (BX201700297); Guangdong Science and Technology Department (2014B020212016, 2017A050501055); Guangzhou Science and Technology Program Projects (2016201604030003, 2016201604030007); Overseas Excellent Professor Project, Ministry of Education of China; and National Key Clinical Discipline.

\section{Availability of data and materials}

The datasets used and/or analyzed during the current study are available from the corresponding author on reasonable request.

\section{Ethics approval and consent to participate}

The animal experiments were performed in accordance with the principles and procedures approved by the Committee on the Ethics of Animal Experiments of The Sixth Affiliated Hospital, Sun Yat-sen University.

\section{Consent for publication}

Not applicable.

\section{Competing interests}

The authors declare that they have no competing interests.

\section{Author details}

'Guangdong Institute of Gastroenterology, The Sixth Affiliated Hospital, Sun Yat-sen University, Guangzhou 510655, Guangdong, China. ${ }^{2}$ Guangdong Provincial Key Laboratory of Colorectal and Pelvic Floor Diseases, The Sixth Affiliated Hospital, Sun Yat-sen University, Guangzhou 510655, Guangdong, China. ${ }^{3}$ Department of Clinical Laboratory, The Sixth Affiliated Hospital, Sun Yat-sen University, Guangzhou 510655, Guangdong, China. ${ }^{4}$ Department of Colorectal Surgery, The Sixth Affiliated Hospital, Sun Yat-sen University, Guangzhou 510655, Guangdong, China.

Received: 1 March 2019 Accepted: 7 July 2019

Published online: 19 July 2019

\section{References}

1. Bray F, Ferlay J, Soerjomataram I, Siegel RL, Torre LA, Jemal A. Global cancer statistics 2018: GLOBOCAN estimates of incidence and mortality worldwide for 36 cancers in 185 countries. CA Cancer J Clin. 2018;68(6):394-424.

2. Heidelberger C, Chaudhuri NK, Danneberg P, Mooren D, Griesbach L, Duschinsky $R$, et al. Fluorinated pyrimidines, a new class of tumourinhibitory compounds. Nature. 1957;179(4561):663-6.

3. Ducreux M, Bouche O, Pignon JP, Mousseau M, Raoul JL, Cassan P, et al. Randomised trial comparing three different schedules of infusional 5FU and raltitrexed alone as first-line therapy in metastatic colorectal cancer. Final results of the federation francophone de Cancerologie digestive (FFCD) 9601 trial. Oncology. 2006;70(3):222-30.

4. Johnston PG, Kaye S. Capecitabine: a novel agent for the treatment of solid tumors. Anti-Cancer Drugs. 2001;12(8):639-46.

5. Kim HK, Choi IJ, Kim CG, Kim HS, Oshima A, Michalowski A, et al. A gene expression signature of acquired chemoresistance to cisplatin and fluorouracil combination chemotherapy in gastric cancer patients. PLoS One. 2011;6(2):e16694.

6. Tournigand C, Andre T, Achille E, Lledo G, Flesh M, Mery-Mignard D, et al. FOLFIRI followed by FOLFOX6 or the reverse sequence in advanced colorectal cancer: a randomized GERCOR study. J Clin Oncol. 2004:22(2):229-37.

7. Pugacheva EN, Ivanov AV, Kravchenko JE, Kopnin BP, Levine AJ, Chumakov PM. Novel gain of function activity of p53 mutants: activation of the dUTPase gene expression leading to resistance to 5 -fluorouracil. Oncogene. 2002;21(30):4595-600

8. Nita ME, Nagawa H, Tominaga O, Tsuno N, Fujii S, Sasaki S, et al. 5fluorouracil induces apoptosis in human colon cancer cell lines with modulation of BCl-2 family proteins. Br J Cancer. 1998;78(8):986-92.

9. Yoo BK, Gredler R, Vozhilla N, Su ZZ, Chen D, Forcier T, et al. Identification of genes conferring resistance to 5 -fluorouracil. Proc Natl Acad Sci U S A. 2009: 106(31):12938-43

10. Loeffler M, Kruger JA, Niethammer AG, Reisfeld RA. Targeting tumorassociated fibroblasts improves cancer chemotherapy by increasing intratumoral drug uptake. J Clin Invest. 2006;116(7):1955-62.

11. Zhang X, Chen Y, Hao L, Hou A, Chen X, Li Y, et al. Macrophages induce resistance to 5 -fluorouracil chemotherapy in colorectal cancer through the release of putrescine. Cancer Lett. 2016;381(2):305-13.

12. Bhola NE, Balko JM, Dugger TC, Kuba MG, Sanchez V, Sanders M, et al. TGF-beta inhibition enhances chemotherapy action against triplenegative breast cancer. J Clin Invest. 2013;123(3):1348-58.

13. Colombo M, Raposo G, Thery C. Biogenesis, secretion, and intercellular interactions of exosomes and other extracellular vesicles. Annu Rev Cell Dev Biol. 2014;30:255-89.

14. Pegtel DM, Cosmopoulos K, Thorley-Lawson DA, van Eijndhoven MA, Hopmans ES, Lindenberg $J$, et al. Functional delivery of viral miRNAs via exosomes. Proc Natl Acad Sci U S A. 2010;107(14):6328-33.

15. Tkach M, Thery C. Communication by extracellular vesicles: where we are and where we need to go. Cell. 2016;164(6):1226-32.

16. Gong M, Yu B, Wang J, Wang Y, Liu M, Paul C, et al. Mesenchymal stem cells release exosomes that transfer miRNAs to endothelial cells and promote angiogenesis. Oncotarget. 2017;8(28):45200-12.

17. Lu J, Liu QH, Wang F, Tan JJ, Deng YQ, Peng XH, et al. Exosomal miR-9 inhibits angiogenesis by targeting MDK and regulating PDK/AKT pathway in nasopharyngeal carcinoma. J Exp Clin Cancer Res. 2018;37(1):147. 
18. Fang JH, Zhang ZJ, Shang LR, Luo YW, Lin YF, Yuan Y, et al. Hepatoma cell-secreted exosomal microRNA-103 increases vascular permeability and promotes metastasis by targeting junction proteins. Hepatology. 2018:68(4):1459-75.

19. Hoshino A, Costa-Silva B, Shen TL, Rodrigues G, Hashimoto A, Tesic Mark $M$, et al. Tumour exosome integrins determine organotropic metastasis. Nature. 2015;527(7578):329-35.

20. Wen C, Huang L, Chen J, Lin M, Li W, Lu B, et al. Gambogic acid inhibits growth, induces apoptosis, and overcomes drug resistance in human colorectal cancer cells. Int J Oncol. 2015;47(5):1663-71.

21. Kho D, MacDonald C, Johnson R, Unsworth CP, O'Carroll SJ, du Mez E, et al. Application of xCELLigence RTCA biosensor Technology for Revealing the profile and window of drug responsiveness in real time. Biosensors (Basel). 2015;5(2):199-222.

22. Jonker DJ, Maroun JA, Kocha W. Survival benefit of chemotherapy in metastatic colorectal cancer: a meta-analysis of randomized controlled trials. Br J Cancer. 2000;82(11):1789-94.

23. Lippert TH, Ruoff HJ, Volm M. Intrinsic and acquired drug resistance in malignant tumors. The main reason for therapeutic failure. Arzneimittelforschung 2008;58(6):261-4.

24. Wang JH, Hendrix A, Hernot S, Lemaire M, De Bruyne E, Van Valckenborgh E, et al. Bone marrow stromal cell-derived exosomes as communicators in drug resistance in multiple myeloma cells. Blood. 2014;124(4):555-66.

25. Hu JL, Wang W, Lan XL, Zeng ZC, Liang YS, Yan YR, et al. CAFs secreted exosomes promote metastasis and chemotherapy resistance by enhancing cell stemness and epithelial-mesenchymal transition in colorectal cancer. Mol Cancer. 2019;18.

26. Chen WX, Liu XM, Lv MM, Chen L, Zhao JH, Zhong SL, et al. Exosomes from Drug-Resistant Breast Cancer Cells Transmit Chemoresistance by a Horizontal Transfer of MicroRNAs. Plos One. 2014;9:4

27. Mathivanan S, Ji H, Simpson RJ. Exosomes: extracellular organelles important in intercellular communication. J Proteome. 2010;73(10):1907-20.

28. Valadi H, Ekstrom K, Bossios A, Sjostrand M, Lee JJ, Lotvall JO. Exosomemediated transfer of mRNAs and microRNAs is a novel mechanism of genetic exchange between cells. Nat Cell Biol. 2007;9(6):654-U72.

29. Qin X, Yu S, Zhou L, Shi M, Hu Y, Xu X, et al. Cisplatin-resistant lung cance cell-derived exosomes increase cisplatin resistance of recipient cells in exosomal miR-100-5p-dependent manner. Int J Nanomedicine. 2017;12:3721-33.

30. Fu X, Liu M, Qu S, Ma J, Zhang Y, Shi T, et al. Exosomal microRNA-32-5p induces multidrug resistance in hepatocellular carcinoma via the PI3K/Akt pathway. J Exp Clin Cancer Res. 2018;37(1):52.

31. Akao Y, Khoo F, Kumazaki M, Shinohara H, Miki K, Yamada N. Extracellular disposal of tumor-suppressor miRs-145 and -34a via microvesicles and 5-FU resistance of human colon cancer cells. Int J Mol Sci. 2014;15(1):1392-401.

32. Ma X, Chen Z, Hua D, He D, Wang L, Zhang P, et al. Essential role for TrpC5containing extracellular vesicles in breast cancer with chemotherapeutic resistance. Proc Natl Acad Sci U S A. 2014;111(17):6389-94.

33. Zhang FF, Zhu YF, Zhao QN, Yang DT, Dong YP, Jiang $L$, et al. Microvesicles mediate transfer of P-glycoprotein to paclitaxel-sensitive A2780 human ovarian cancer cells, conferring paclitaxel-resistance. Eur J Pharmacol. 2014;738:83-90.

34. Yang SJ, Wang DD, Li J, Xu HZ, Shen HY, Chen X, et al. Predictive role of GSTP1-containing exosomes in chemotherapy-resistant breast cancer. Gene. 2017:623:5-14

35. Coles BF, Kadlubar FF. Detoxification of electrophilic compounds by glutathione S-transferase catalysis: determinants of individual response to chemical carcinogens and chemotherapeutic drugs? Biofactors. 2003; 17(1-4):115-30

36. Zhong Z, Wen Z, Darnell JE Jr. Stat3: a STAT family member activated by tyrosine phosphorylation in response to epidermal growth factor and interleukin-6. Science. 1994:264(5155):95-8.

37. Birner P, Toumangelova-Uzeir K, Natchev S, Guentchev M. STAT3 tyrosine phosphorylation influences survival in glioblastoma. J Neuro-Oncol. 2010; 100(3):339-43.

38. Spitzner M, Roesler B, Bielfeld C, Emons G, Gaedcke J, Wolff HA, et al. STAT3 inhibition sensitizes colorectal cancer to chemoradiotherapy in vitro and in vivo. Int J Cancer. 2014;134(4):997-1007.

39. Qin A, Yu Q, Gao Y, Tan J, Huang H, Qiao Z, et al. Inhibition of STAT3/cyclinD1 pathway promotes chemotherapeutic sensitivity of colorectal caner. Biochem Biophys Res Commun. 2015;457(4):681-7.

40. Lindner A. Cytochemical effects of 5-fluorouracil on sensitive and resistant Ehrlich ascites tumor cells. Cancer Res. 1959;19(2):189-94.
41. Schust J, Sperl B, Hollis A, Mayer TU, Berg T. Stattic: a small-molecule inhibitor of STAT3 activation and dimerization. Chem Biol. 2006;13(11):1235-42.

42. Madhavan B, Yue S, Galli U, Rana S, Gross W, Muller M, et al. Combined evaluation of a panel of protein and miRNA serum-exosome biomarkers for pancreatic cancer diagnosis increases sensitivity and specificity. Int J Cancer. 2015;136(11):2616-27.

\section{Publisher's Note}

Springer Nature remains neutral with regard to jurisdictional claims in published maps and institutional affiliations.
Ready to submit your research? Choose BMC and benefit from:

- fast, convenient online submission

- thorough peer review by experienced researchers in your field

- rapid publication on acceptance

- support for research data, including large and complex data types

- gold Open Access which fosters wider collaboration and increased citations

- maximum visibility for your research: over $100 \mathrm{M}$ website views per year

At $\mathrm{BMC}$, research is always in progress.

Learn more biomedcentral.com/submissions 